\title{
IDENTIFICATION OF RICE CROP PHENOLOGY USING SCATSAT-1 KU-BAND SCATTEROMETER IN PUNJAB AND HARYANA
}

\author{
Pushkar Gaur $^{1}$, Preeti Tahlani ${ }^{1}$, Rojalin Tripathy ${ }^{2}$, B. K. Bhattacharya ${ }^{2}$ and S.S Ray ${ }^{1}$ \\ ${ }^{1}$ Mahalanobis National Crop Forecast Centre, DAC\&FW, New Delhi, India - gaur.pushkar8@gmail.com, preeti.tahlani@gov.in, \\ shibendu.ncfc@nic.in \\ ${ }^{2}$ Space Applications Centre, Ahmedabad, Gujarat, India - (rose_t, bkbhattacharya)@sac.isro.gov.in
}

\section{Commission III, WG III/10}

KEYWORDS: SCATSAT-1, Ku band, Scatterometer, Rice Phenology

\begin{abstract}
The present study was carried out to analyse rice crop phenology using SCATSAT-1 Scatterometer data. Owing to its higher frequency, Ku-band responds to the dormant elements of surface, corresponding to top of crop canopy. The Ku-band backscatter behaviour is influenced by the structure, moisture content and the roughness of the top canopy which varies with different crop stages. Rice growth undergoes three main phenological stages viz, maximum tillering giving a scattered rough surface (first peak); maximum vegetative stage with a smooth top appearance (first minima after puddling); and the panicle development stage giving more scattering due to the spikelets (second peak). This study aimed at deriving these three stages of rice crop. Rice crop map generated, under FASAL project, using Sentinel-1 SAR data has been utilized and further the sub-pixel area within the SCATSAT-1 pixel. The daily Sigma- 0 product was utilised for estimation of dates of major phenological stages of rice crop. A software tool was developed to generate the three phenological stages at $2 \mathrm{~km}$ pixel level using the time series backscatter coefficient in VV polarization over rice pixels using polynomial curve fitting. It was observed that peak tillering stage coincides with the first maxima, first minima coincides with the maximum vegetative stage and second maxima coincides with the peak heading or panicle formation stage of the crop. The validation was carried out using ground information from crop cutting experiments and ground truth data. Validation result showed 4 to 12 days difference in maximum vegetative stage.
\end{abstract}

\section{INTRODUCTION}

Microwave remote sensing has a high potential to map crop during kharif season as the optical data is often hampered by cloudy conditions. This study demonstrates the capability of high temporal resolution of the ku-band scatterometer data for rice crop phenology identification, which is essential for crop growth modelling using SCATSAT-1. The SCATSAT1 is an active Scatterometer designed to measure ocean surface wind velocity. The sensor transmits signals at regular interval and receives the energy back scattered by the targets on the Earth. Space Application Centre, ISRO, generates Level 1B product from the sensor data. The Level 1B product carries backscattering coefficient (or sigma0) and other radiometric parameters along with geolocation information. The correlation between backscattering coefficient $\left(\sigma^{0}\right)$ and plant biophysical parameters has been observed to be highly significant for quantification of the same (e.g., Bouman, 1991; Le Toan, Lopes, \&Huet, 1984;Ulaby, Allen, Eger, \&Kanemasu, 1984). Previous studies have been carried out over rice crop using ground based scatterometer and multi-frequency, multi-angular observations. The higher frequency bands ( $\mathrm{Ka}, \mathrm{Ku}$ and $\mathrm{X}$ ), that interacts mainly with topmost layer of crop, were found to be sensitive to early growth changes when the LAI(Leaf Area Index $)<1.5$, which reveals that the backscattering coefficient increases with increasing LAI and loses sensitivity thereafter (Inoue et al., 2002). The backscattering coefficient decreases towards heading stage and then subsequently increases until harvest, which is a characteristic feature of higher frequencies and is not observed in lower frequencies ( $\mathrm{C}$ and $\mathrm{L}$ band). It has also been observed that this dual peak is more observable in $\mathrm{VV}$ cross polarization while is less obvious in $\mathrm{HH}$ - polarization.

\section{STUDY AREA}

The study area included two major rice growing states of India, Punjab and Haryana lying in the western part of Indo-Gangetic plane. In both states, rice is grown in sandy-loam soil under fully irrigated condition, which provides uniformity in cropped area distribution. The rice crop is grown under wetland in which the fields are flooded and 20-22 days old saplings are transplanted. The crop is grown in study area for 120 days cycle. The transplanting starts from June $3^{\text {rd }}$ week and harvesting takes place in September end and till October $2^{\text {nd }}$ week in study area.

\section{DATA USED}

Data from SCATSAT 1 was utilised for this study. SCATSAT 1 carries a pencil beam wind scatterometer operating in $\mathrm{Ku}$-band of frequency $13.515 \mathrm{GHz}$. Super resolved L4_India sigma naught $\left(\sigma^{0}\right)$ product with $2 \mathrm{~km}\left(0.02^{0}\right)$ spatial resolution from June to November, 2018 generated at Space Application Centre, ISRO, Ahmedabad was utilised for this study (Early and Long 2001).

\begin{tabular}{ll}
\hline Parameter & Outer beam \\
\hline Orbital altitude & $723 \mathrm{~km}$ \\
Instrument frequency & $13.515 \mathrm{GHz}$ (Ku-band) \\
Spatial Resolution & $25 \mathrm{~km} \mathrm{x} \mathrm{25} \mathrm{km} \mathrm{grid}$ \\
& $\mathrm{VV}$ \\
Polarization & $1840 \mathrm{~km}$ \\
Swath width & $920 \mathrm{~km}$ \\
Scanning circle radius & L4 India 2 km resolution \\
Product Used & \multicolumn{2}{c}{ Table 1: Description of SCATSAT Data used }
\end{tabular}


Multi date Sentinel 1 VV-polarisation data was used under FASAL project to generate rice crop map of Punjab and Haryana. The final rice map generated is of spatial resolution 20 $\mathrm{m}$, which was utilised for identifying rice pixel in SCATSAT image.

\section{METHODOLOGY}

The flowchart depicting the methodology used for the study is shown in figure 1 .

\subsection{Rice crop map generation}

Rice crop map of the study states were generated under FASAL project using multi-temporal Sentinel-1 SAR data. It is a twostep process, first, an optimum date for paddy area classification was selected. An unsupervised classification was carried out on multi-level stacked dataset, in which mean for each class is calculated. Depending on the backscatter value pertaining to sowing dates, the optimum date for area was obtained. In second step, Hierarchical decision rule-based classification was carried out using the selected layers.

A grid of cell size equivalent to SCATSAT pixel size $(2 \mathrm{~km})$ was created. The $20 \mathrm{~m}$ rice crop map generated using Sentinel-1 data was overlaid on the SCATSAT grid. Grid cells containing more than $50 \%$ crop area were identification as rice pixel in SCATSAT data and were further used for the study. This ensures that the rice mask generated at spatial resolution of SCATSAT1 consists of sub-pixel rice cropped area greater than $50 \%$.

This Rice mask generation at SCATSAT resolution was done using the GIS software (ERDAS Imagine and ArcGIS). A temporal stack of the SCATSAT Rice mask was used further analysis.

\subsection{SCATSAT data processing}

4.2.1 Data preparation: Super-resolved Level 4 India sigma naught $\left(\sigma^{0}\right)$ product of SCATSAT 1 was utilised for this study. The calibration of data is done using slope and offset method for conversion of $\mathrm{DN}$ to backscatter values $(\mathrm{dB})$. The equation described as,

$$
\operatorname{Sigma} 0=0.001 * \mathrm{DN}-50.0
$$

Daily temporal VV-polarised sigma naught values $\left(\sigma^{0}\right)$ from June 1,2018 to November 9, 2018 i.e., from DOY 151 to 313 has been utilised for estimation of phenology dates.

4.2.2 Phenology dates extraction The Ku- band exhibits a phenomenal feature of dual peak curvature of temporal backscatter values, first at maximum panicle stage and second at the stage of maturity while the minima in between corresponds to heading stage (Inoue et al.,2002). The $6^{\text {th }}$ order polynomial curve fit describes the best fit for the SCATSAT1 temporal backscatter values for extraction of dates corresponding to the 3 phenological stages of rice crop.

A software tool was developed in Python to read the temporal stack of SCATSAT data generated in previous stage and apply polynomial curve fitting at each pixel to identify the dates for major phenological stages of rice crop. A 6th order polynomial curve best describes the rice crop phenology. The extracted dates for each pixel are then used for generating the map for different crop stages.

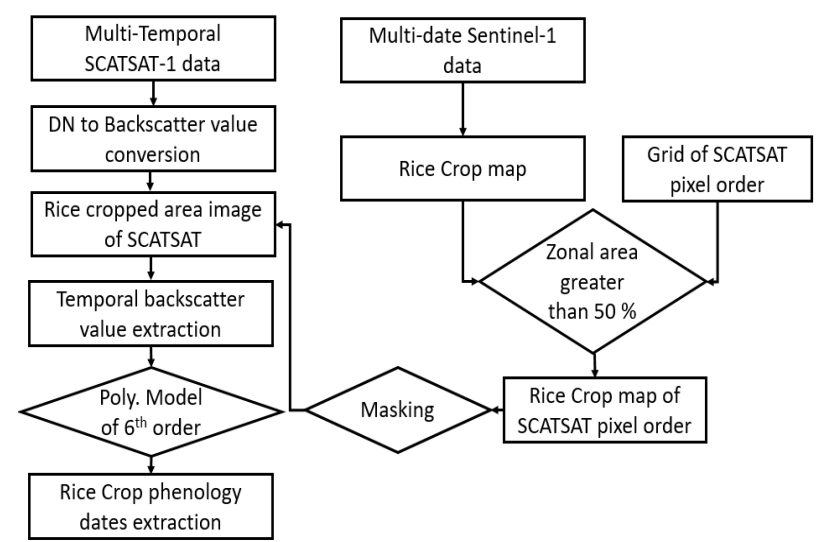

Figure 1: Methodology Followed

\section{RESULTS AND DISCUSSION}

The rice crop phenology was derived using multi-temporal SCATSAT $1 \sigma^{0}$ L4-India data from DOY 151 to 313 . For identification of rice crop pixels in SCATSAT image, rice crop map generated under FASAL project using multi-temporal Sentinell SAR data acquired during June to September was utilised. The accuracy of the classification is above $90 \%$ which is established by intensive ground truth done during the growing period. The derived rice map was used as reference for selection of rice cropped area of SCATSAT1 pixel order $\left(0.02^{\circ}\right)$. The cropped land in Punjab and Haryana consists of predominantly large contiguous paddy areas. These areas have extensions greater than $2 \mathrm{~km}$, hence SCATSAT pixel can be considered as synthetic rice pixel for analysis.

\subsection{Temporal Backscatter Behaviour}

The temporal behaviour of $\sigma^{0}$ at rice pixels is shown in figure 2 . The $\sigma^{0}$ is plotted as function of Julian dates. Temporal behaviour of SCATSAT $1 \mathrm{Ku}$ - band backscatter shows a dual peak behaviour (Inuoe et al.,2002). The backscatter value at transplanting stage ranges from -13 to $-14 \mathrm{~dB}$ in both the study states. The initial low backscatter corresponds to transplanting stage of crop which is identified by its flooded state. The first peak is observed after approx. 40-50 days from the date of transplanting, signifies the maximum tillering stage. After the first peak, a steady decline is observed for 40 days, the backscatter minima of which corresponds to the heading stage. The value of backscatter increases henceforth up to the stage of maturity. The value of backscatter from transplantation to maturity ranges from -9 to $-14 \mathrm{~dB}$.

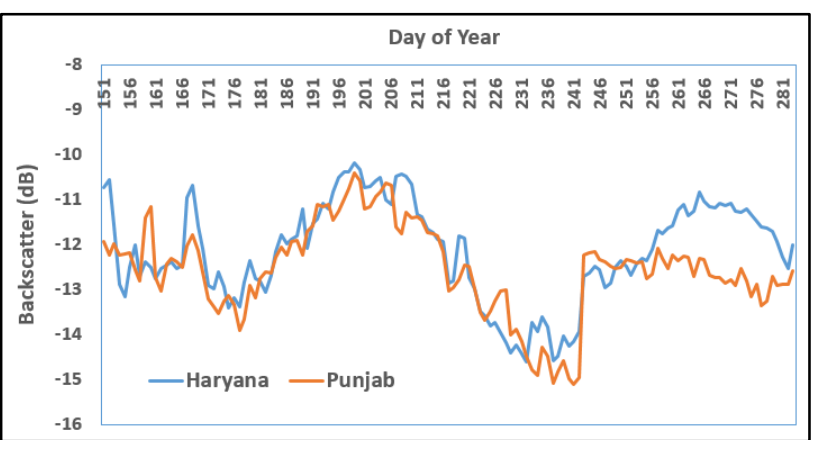

Figure 2: Temporal behaviour of backscatter for Rice Pixel 
The physical significance of behaviour of $\sigma^{0}$ can be described by three phenological stages i.e., maximum tillering, heading stage and maturity stage.

4.2.3 Maximum tillering stage: The backscatter at initial i.e., at freshly transplanted/flooding stage was observed in the range $-13 \mathrm{~dB}$ to $-14 \mathrm{~dB}$. The practice of paddy cultivation which includes flooding the field just after the transplanting to protect the seedling makes it significant to be detected using radar remote sensing. The growth of seedlings was clearly detectable as the $\sigma^{0}$ values increases with growing stem density. The value reached at its maximum value at maximum tillering stage. Similar results has been reported from previous study conducted for rice crop using Quicksat (Oza and Parihar, 2007) and by ground based scatterometer observations conducted for rice crop using large angle VV-polarised Ku-band by Inoue et al (2002). The intensive work done by Inoue et al, demonstrated that the value of backscatter increases until the value of LAI is 1.5 after the dip occurred due to flooding. While it was observed that the growth was not as significant as that in ground-based experiment, which may have occurred due to averaged response function of the satellite pixel. The phenomenon becomes less conclusive with increase in heterogeneity inside the pixel. The similar findings have been reported by Oza and Parihar, 2007 in similar experiment using Quicksat.

The maximum tillering stage dates derived using this study is shown by generating the maps for Punjab and Haryana in Figure $3 \& 4$.

4.2.4 Heading Stage: The minima was attained at heading stage. After the first peak value, $\sigma^{0}$ declines for 40 subsequent days. The value at minima ranged from -12 to $-14 \mathrm{~dB}$. The backscatter of Ku-band is dominated mainly by top of the crop cover hence the value decreased as the stem and other vertical structures were masked by leaf growth during this stage. The leaf surface provides a smoother object to the electromagnetic wave to reflect and hence $\sigma^{0}$ decreased with increase in leaf area index. This is in contrary to the behaviour of C-band where the minima is obtained at the transplanting stage. Thus, behaviour of $\mathrm{Ku}$-band is complementary to the $\mathrm{C}$-band. The dates for heading stage derived from this study is shown in maps in figure $5 \& 6$ for Punjab and Haryana respectively. They were compared with the maximum vegetative stage derived for Rice crop from MODIS NDVI product. The maximum vegetative stage corresponds to peak NDVI period in the MODIS multitemporal data. There is a good match between the patterns of MODIS derived product and the ScatSat output, showing the overall accuracy of ScatSat derived heading stage. The matching was better in Haryana than Punjab, due to cloudy condition in Punjab. Peak NDVI date is following the minima date.The difference of Minima date (of ScatSat) and maximum NDVI date (of MODIS)was approximately 10 days.

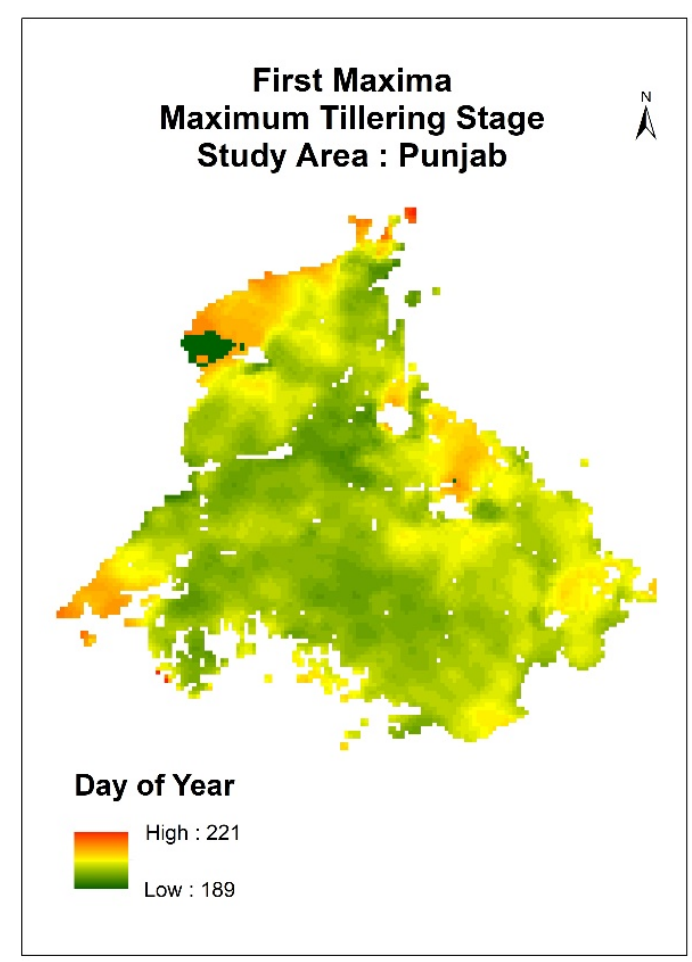

Figure 3: Maximum Tillering Stage of Rice for Punjab

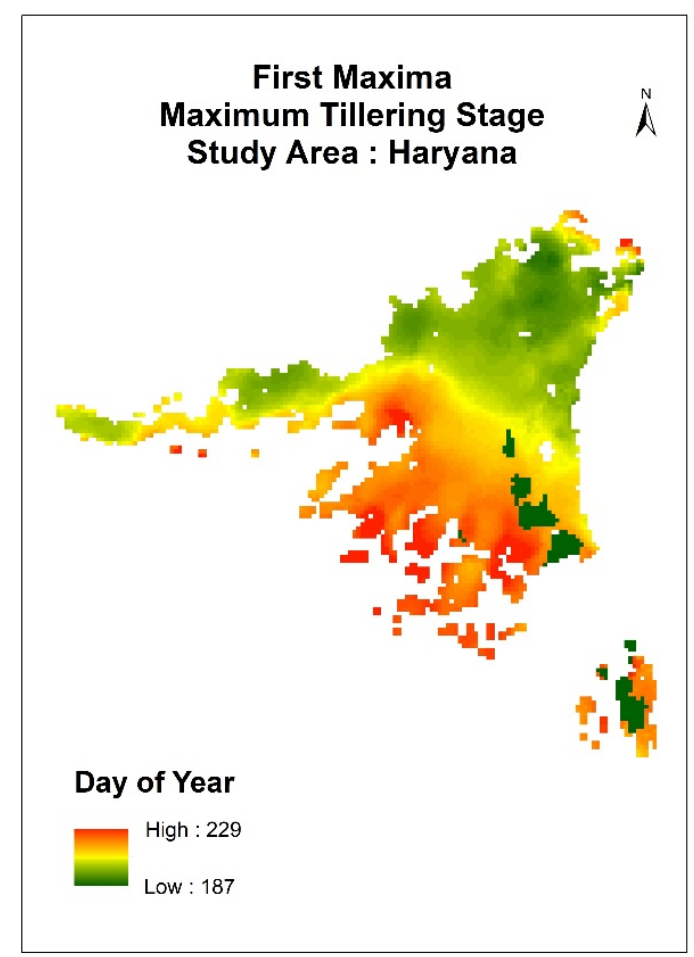

Figure 4: Maximum Tillering Stage of Rice for Haryana

The number of days of Transition from max tillering to heading is shown in figures $7 \& 8$ for Punjab and Haryana respectively. 


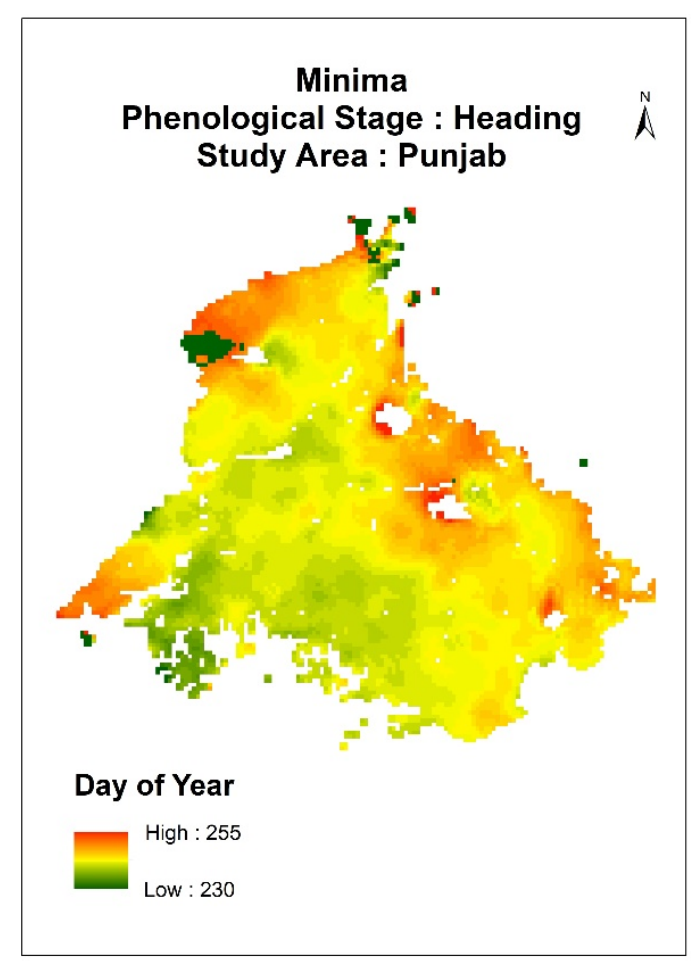

Figure 5: Heading stage of Rice for Punjab derived from ScatSat Data

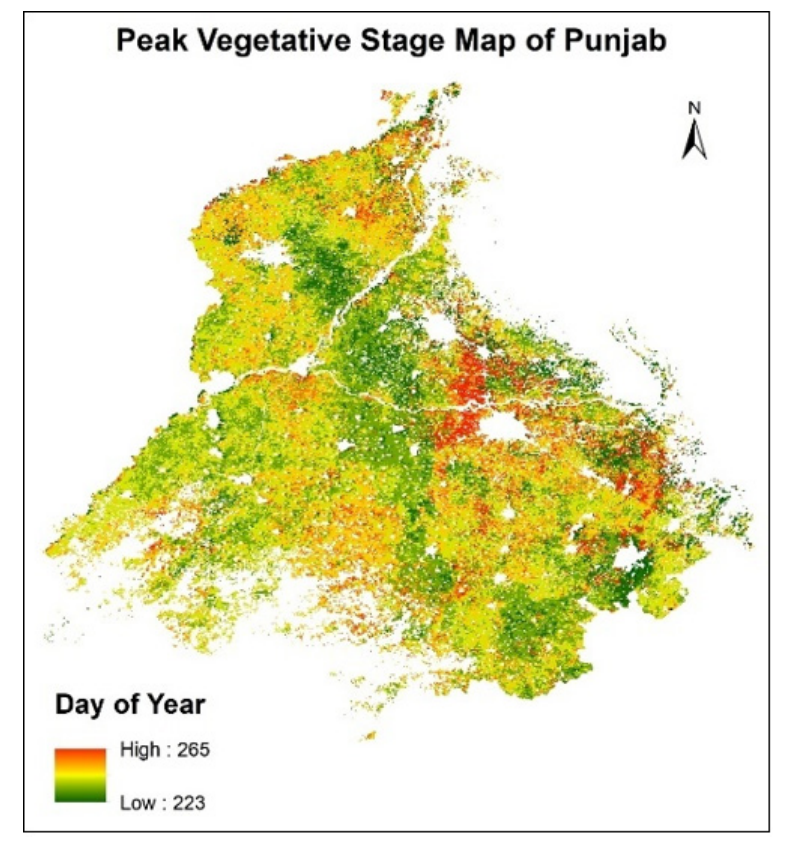

Figure 6 : Peak vegetative stage of Punjab derived from MODIS NDVI data product.

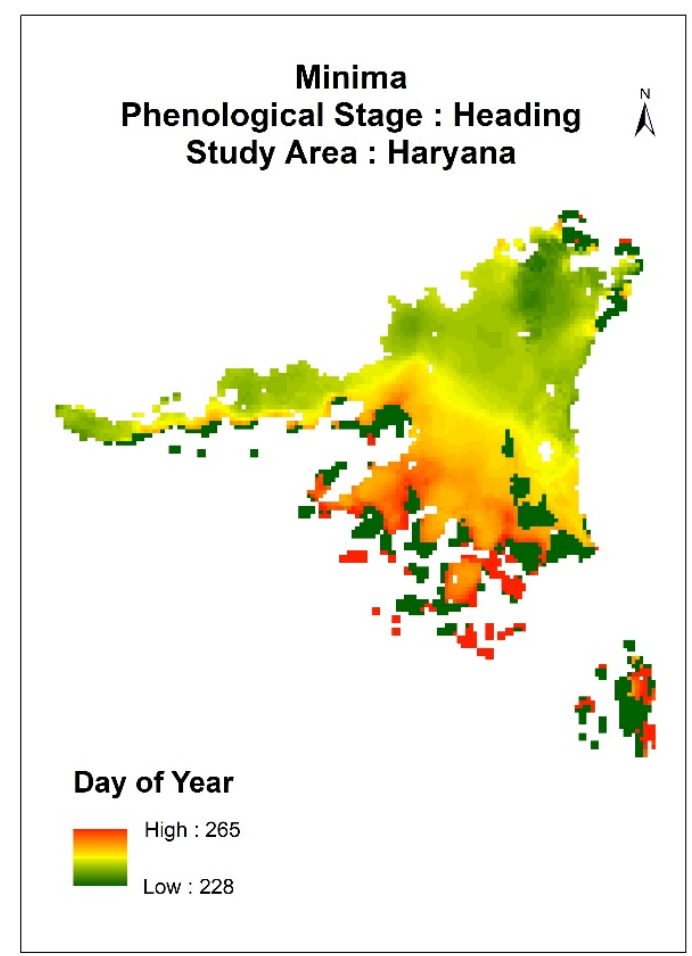

Figure 7: Heading stage of Rice for Haryana derived from ScatSat Data

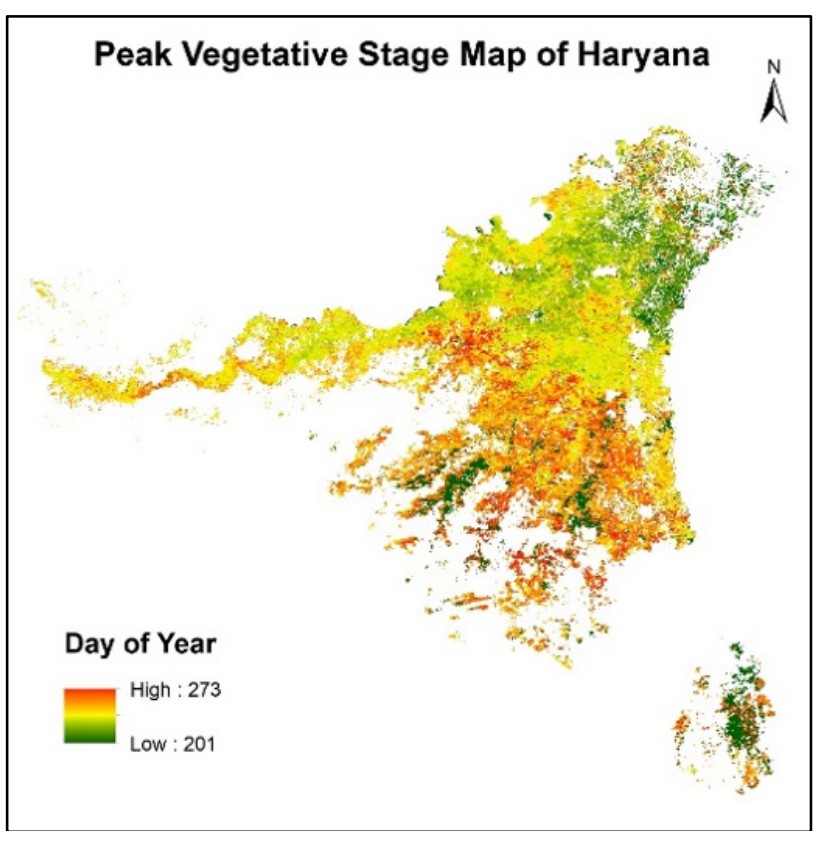

Figure 8: Peak vegetative stage of Haryana derived from MODIS NDVI data product. 


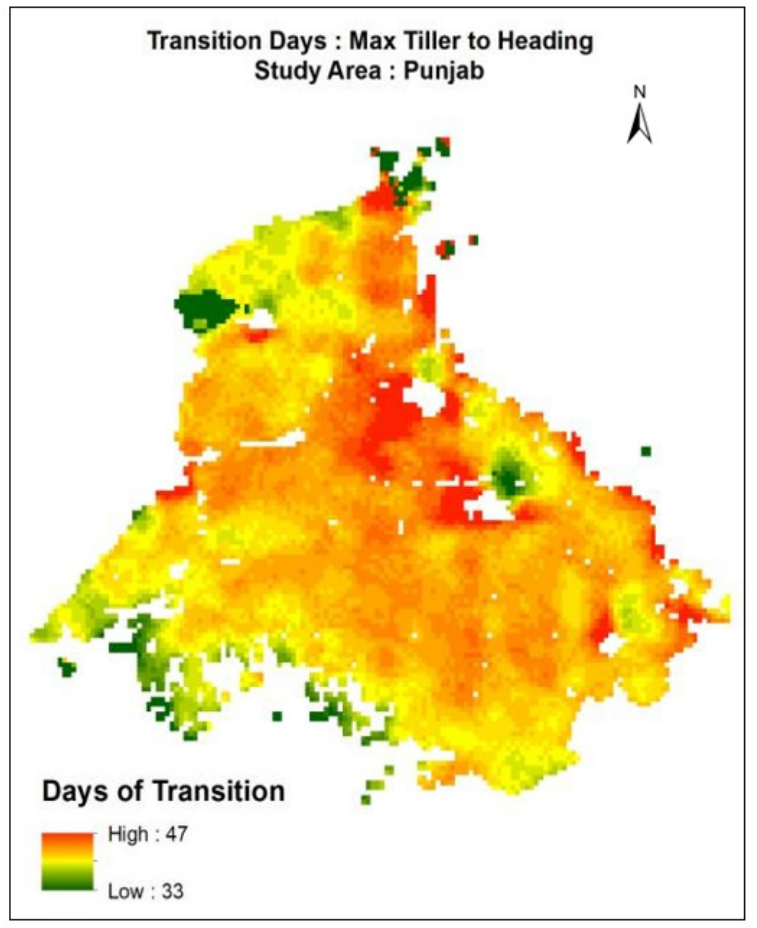

Figure 9: Transition to Heading of Rice crop in Punjab

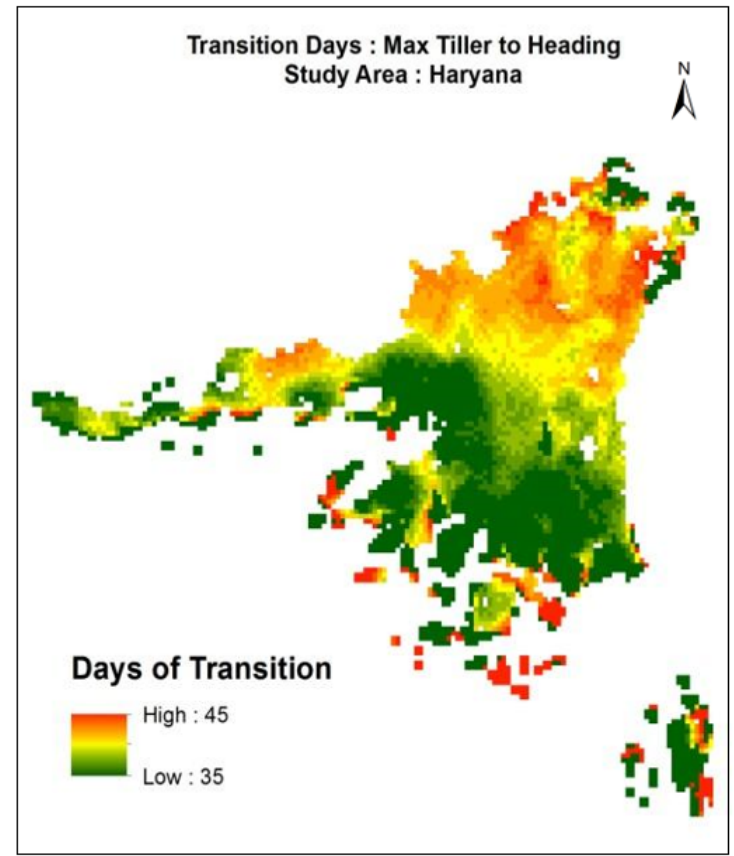

Figure 10: Transition to Heading of Rice crop in Haryana

4.2.5 Maturity Stage: The rise in value of backscatter was observed with the initiation of panicle. The plant morphological features such as spikelet, panicle and grain increases the surface roughness and hence the surface scattering. Similar results have been reported by Inoue et al, (2002) for paddy crop using high frequency $(\mathrm{Ka}, \mathrm{Ku}, \mathrm{X})$ ground scatterometer at large angles particularly in VV-polarization. The dates for maturity are shown in maps in figure $11 \& 12$ for Punjab and Haryana respectively. It takes around 30 days to reach from heading to maturity stage as shown in figure $13 \& 14$ for Punjab and Haryana respectively.

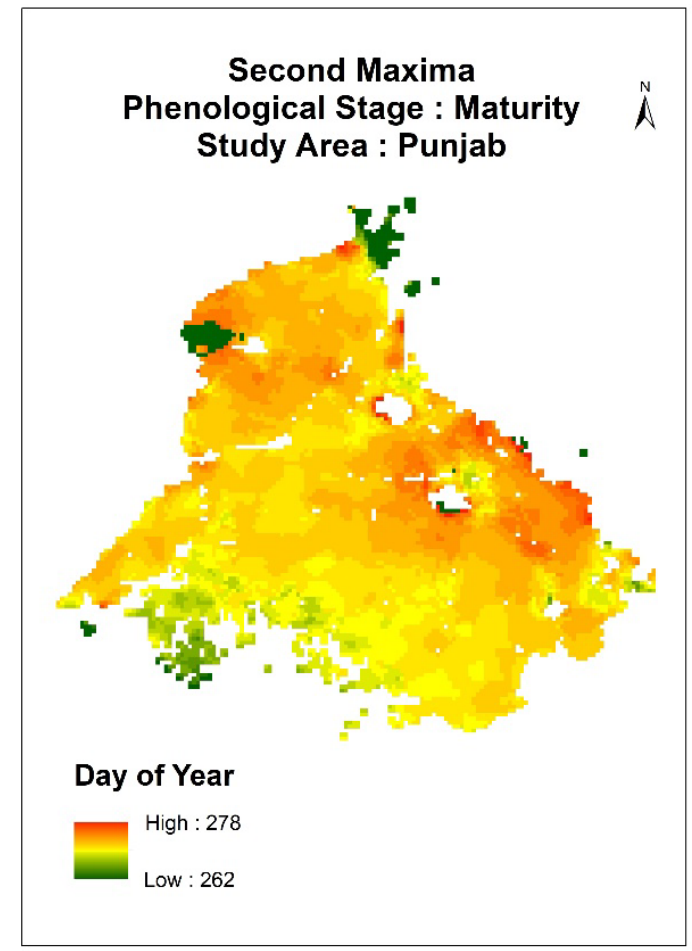

Figure 11: Maturity stage of Rice crop in Punjab

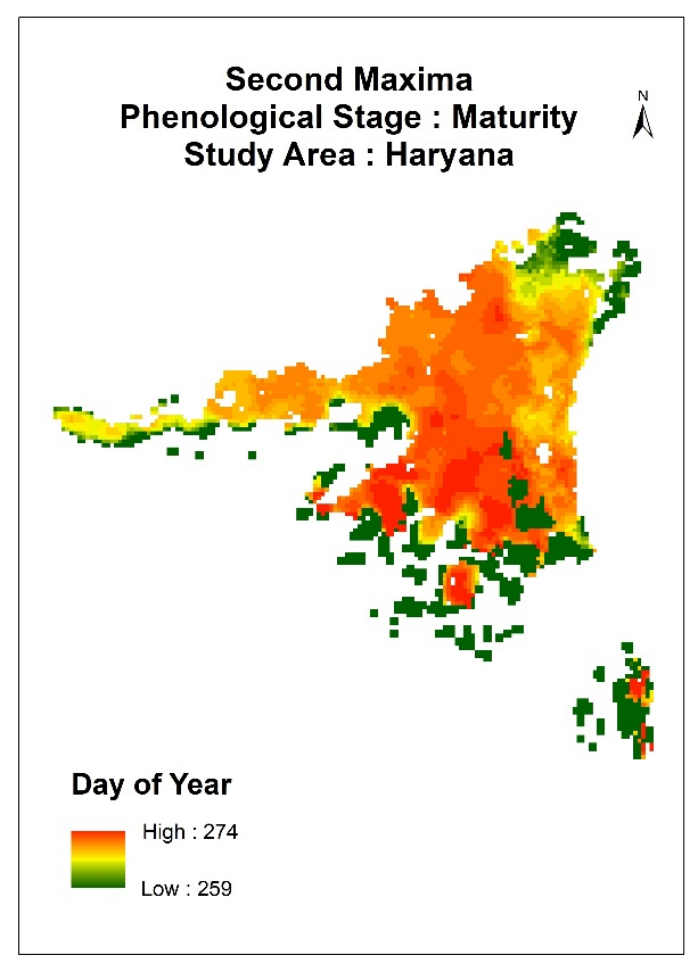

Figure 12: Maturity stage of Rice crop in Haryana

4.2.6 Plant Phenology Extraction: The present study utilises $6^{\text {th }}$ order polynomial-based model for phenology dates extraction over backscatter from multi-date SCATSAT $1 \sigma^{0}$ images. The figure 15 shown below is the result of fit obtained over the rice area of Haryana. The dates obtained using the polynomial model for maximum tillering, heading and maturity stage for pixel are at day of year 197 (16 July), 240 (28 August) and 274 ( 1 October) respectively which matches with ground truth observations, the crop cutting experiment at the site was 
done on 291 (18 November). The simulated values were found to have good proximity with the observed values validated from ground truth data. It was observed that SCATSAT pixel with greater percentage of cropped area showed more correlation with ground truth data. The SCATSAT pixel with sub-pixel rice cropped area greater than $50 \%$, the dual peak behaviour was observed to be significant while the curvature loses its property as the area was reduced furthermore.

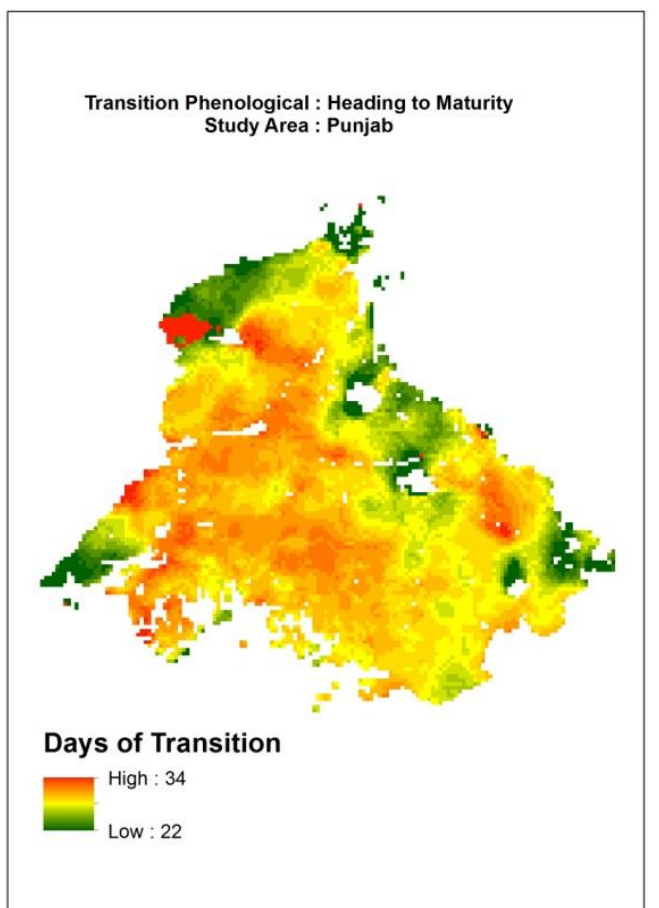

Figure 13: Transition days from Heading to Maturity for Punjab

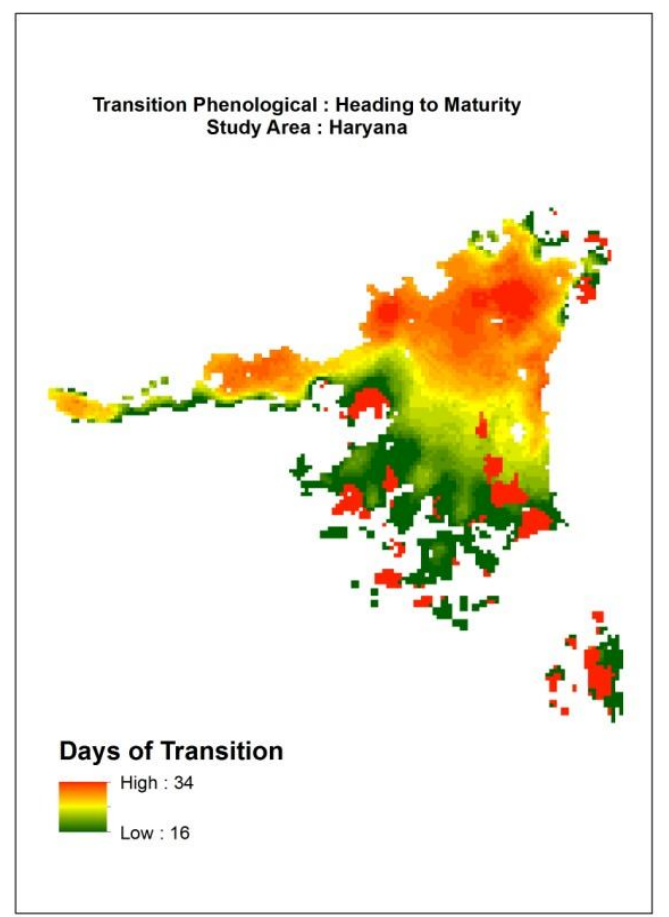

Figure 14: Transition days from Heading to Maturity for Haryana

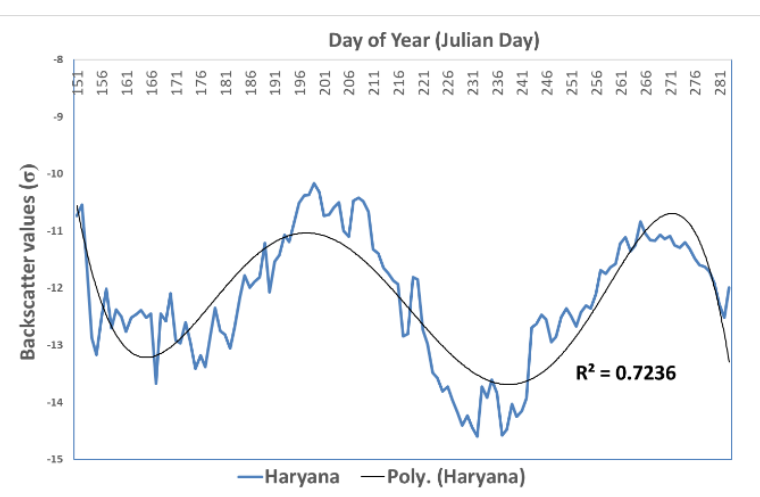

Figure 15: Polynomial Curve fitted over rice pixel

\section{CONCLUSION}

This paper attempted to map rice crop phenology using SCATSAT $1 \mathrm{Ku}$-Band data. Temporal L4- India $\sigma^{0}$ data from 151 day of year (DOY) to 313 DOY was utilised for the study. The temporal backscatter values demonstrated the dual peak feature corresponding to the crop phenological characteristics. This observation matched well with previous works done using Ku-band scatterometer by Inoue et al (2002) and Oza et al. (2007). The first backscatter maxima coincided with max tillering stage, which showed a transition of approximately 40 days to reach the minima corresponding to heading stage. The gradual growth for approximately 30 days took place to reach second maxima corresponding to maturity. The heading stage derived from ScatSat data matched well with the maximum vegetative stage derived from MODIS NDVI product.

\section{ACKNOWLEDGEMENTS}

The work was carried out under the ScatSat Utilisation programme of Space Applications Centre, ISRO. Authors are thankful to the Additional Secretary, DAC\&FW and Joint Secretary (IT), DAC\&FW and the Director and Deputy Director (EPSA), SAC for the encouragement and support for this study. Thanks are due to FASAL team for providing the Rice Mask and CCE data used for the study. The authors are also thankful to state departments and state remote sensing centres of Punjab and Haryana for their support during Ground truth data collection for the project.

\section{REFERENCES}

Brisco, B. and Brown, R.J., 1998, Agricultural applications with radar. In Principles and Applications in Imaging Radar, F.M. Henderson and A.J. Lewis (Eds), pp. 381-406 (New York: Wiley).

EARLY, D.S. and LONG, D.G., 2001, Image reconstruction and enhanced resolution imaging from irregular samples. IEEE Transactions on Geoscience and Remote Sensing, 39, 291-302.

Inoue, Y., Kurosu, T., Maeno, H., Uratsuka, S., Kozu, T., Dabrowsk-Zielinska, K. and Qi, J., 2002, Season-long daily measurements of multifrequency $(\mathrm{Ka}, \mathrm{Ku}, \mathrm{X}, \mathrm{C}$, and $\mathrm{L})$ and full-polarization backscatter signatures over paddy rice field and their relationship with biological variables. RemoteSensing of Environment, 81, 194-204.

Le Toan, T., Lopes, A., \& Huet, M. (1984). On the relationship between radar backscattering coefficient and vegetation canopy characteristics. In: Proceedings of international geoscience and 
remote sensing symposium 1984 ( pp. 155-160). Strasburg, France: ESA special publication.

Oza, S. R. and Parihar, J. S. (2007) 'Evaluation of Ku-band QuikSCATscatterometer data for rice crop growth stage assessment', International Journal of Remote Sensing, 28:16, $3447-345$
Ulaby, F. T., Allen, C. T., Eger, G., \& Kanemasu, E. T. (1984). Relating the microwave backscattering coefficient to leaf area index. Remote Sensing of Environment, 14, 113-133.

Ulaby, F.T. and Bush, T.F., 1976, Monitoring wheat growth with radar. Photogrammetric Engineering and Remote Sensing, $42,557-568$. 